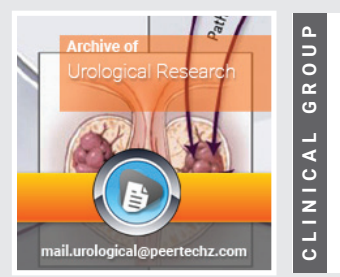

\title{
Failed repair of isolated female epispadias: Insights and outcome of single stage repair
}

\author{
Abdul Rouf Khawaja ${ }^{1 *}$, Farzana Bashir', Javaid Magray², \\ Ashiq hussain ${ }^{2}$, Sajad Malik ${ }^{1}$, Arif Hamid ${ }^{1}$ and Mohd Saleem \\ Wani' $^{1}$
}

${ }^{1}$ Consultant, Department of Urology, Sheri Kashmir Institute of Medical Sciences Srinagar Soura Jammu and Kashmir 190011, India

${ }^{2}$ Senior Resident, Department of Urology, Sheri Kashmir Institute of Medical Sciences Srinagar Soura Jammu and Kashmir 190011, India

Received: 04 April , 2020

Accepted: 24 April, 2020

Published: 25 April, 2020

*Corresponding author: Dr. Abdul Rouf Khawaja, Assosciate Professor Urology, Sheri Kashmir Institute of Medical Sciences, Srinagar Jand k 190011, Tel. no: 9419087992; E-mail:roufkhawaja@rediffmail.com

Keywords: Cutaneous continent diversion; Female Epispadias; Genitoplasty; Urinary incontinence

https://www.peertechz.com

\section{Check for updates}

\begin{abstract}
Female epispadias without exstrophy is a very rare entity and occurs one in 480,000 female population. Early surgical reconstruction of the bladder neck,urethra and external genitalia is important in establishing urinary continence and to reduce psychological stress on the parents and child.In this case report we present a 25 year unmarried female presented with failure to achieve continence after bladder neck reconstruction at age 4year by urologist. Due to previous surgical failure, Patient developed psychological problems with poor esteem and wants a procedure which makes her life socially acceptable. A continent cutaneous urinary diversion was done at a single procedure with a follow up of 02 year. Patient is continent with pouch capacity about $400 \mathrm{ml}$ and emptying her pouch every $4 \mathrm{hrly}$ and actively involving in social activities, enjoying an excellent lifestyle, accepted body image and good personal satisfaction.
\end{abstract}

\section{Introduction}

Female Epispadias is a rare congenital anomaly occurring in one in 480,000 female population [1]. The condition is often missed at first examination but should be diagnosed immediately at birth. Diagnosis can only be made after separating the labia. Early diagnosis and surgical reconstruction of the bladder neck,urethra and external genitalia are relevant to improve the chance for urinary continence [2]. In most instances the vagina and internal genitalia are normal. Lack of labial anterior commissure, bifid clitoris, short and wide urethra and immature bladder neck are main properties of this pathology.

\section{Case report}

A 25-year old unmarried female presented to our outpatient department because of total urinary urinary incontinence both day and night. She had been previously evaluated and surgically treated at age of 04 years as young dees procedure only. She was consulted by many urologist and multiple cystoscopies and no proper diagnosis was made.On evualation of records only bladder neck reconstruction as young dees procedure was done. urethral and external genitalia reconstruction was not addressed.Due to failure of treatment,the patient developed psychological problems and was totally staying indoor in home. On physical examination and cystoscopy revealed type 3 female epispadias with bifid clitoris (Figure 1). External genitalia skin was excoriated due to continuous leakage of urine and with multiple pustular lesions over the external genitalia. On cystoscopy no external urethral meatus with incompetent bladder neck and a small capacity bladder about the volume of $50 \mathrm{ml}$. Both ureteric orifices were laterally placed. An midline scar was present infraumblical region. No other skeletal abnormality was present. An CECT KUB was done for evualating upper tracts and bladder. Upper tracts were normal and no bladder radiology was possible as patient was not able to hold urine. Micturating Cystometrogram was done which reveals $\mathrm{B} / \mathrm{L}$ refluxing ureters with capacity of only $35-45 \mathrm{ml}$ on 
closing bladder neck by foley's cathter. Urodynamics was tried twice but was inconclusive as the patient was not able to hold urine because of severe epispadias. Because of earlier failed reconstruction and never attained continence with the reason hardly much bladder template for reconstruction and even though requires anti incontinence procedure for continence after augmentation. Pyocystitis is unlikely as there is type 3 female epispadias and bladder neck is visible on genital examination. For closure of bladder neck with augmentation cystoplasty chance of fistula was risk and even though she needs mitrofanoff for intermittent procedure All pros and cons about surgical reconstructive procedures were explained in detail. Patient was insisting one time durable procedure. Patient consented for continent catheterizable reservoir made from ileum (Figure 2). Patient is on regular follow up for the last 02 year with a pouch capacity about $400 \mathrm{ml}$ and is continent actively involved in indoor and outdoor activities.

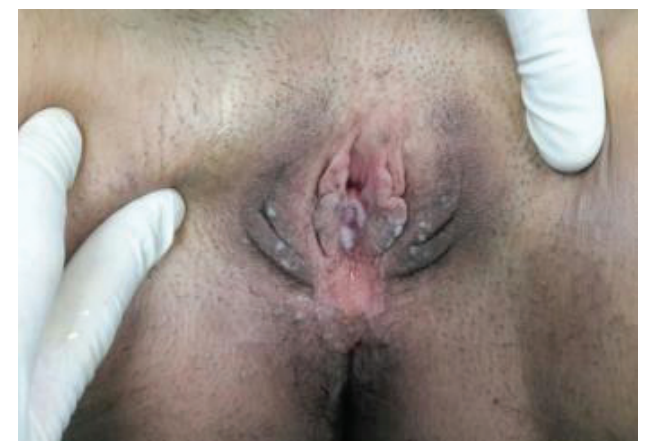

Figure 1: Type 3 Epispadias.

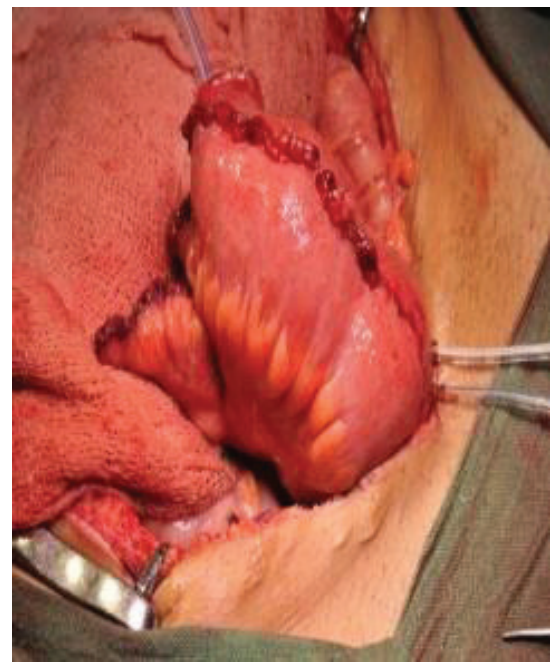

Figure 2: Continent neo bladder from lleum.

\section{Discussion}

The aetiology of female epispadias is unclear and is considered possibly to be the result of combination of several genetic and environmental factors [3]. Associated anomalies are commonly confined to the urinary tract with an incidence of vesicoureteric reflux at $30-75 \%$. Incontinence is not only a common complaint in female epispadias but is also associated with noticeable anatomical features like an absent or bifid clitoris [4] depressed mons and ill developed labia. The bladder is often small with poorly developed bladder neck and incompetent sphincteric mechanism. Early diagnosis allows early parenteral counseling and a planned surgical reconstructive procedure at 4to 5 years of age when the bladder capacity reaches approximately 80 to $85 \mathrm{ml}$. In our case report of adult female epispadias with type 3 variant and early reconstructive surgery as young dees procedure at age of 04 years, three options were given to the patient for the female epispadias. First option using bladder template with augmentation of bowel, urethral reconstruction, genitoplasty and optional sling procrdure for incontinence and continuous indwelling catheterization if fails to void. Second option was closure of bladder neck with augmentatation of bowel and continent catheterizable pouch. In second option risk of bladder fistula was explained in view of previous bladder neck surgery. Third option was leaving bladder and make an continent catheterizable reservoir from ileum and incorporate ureters into the reservoir. Patient agreed for third option and the issues were bladder in situ. As the patient was never continent after toilet training, so no feeling of incomplete emptying and spasm will occur.Moreover if need arises cystoscopy is possible for the native bladder. In our case it was an isolated type 3 epispadias, no adenocarcinoma of retained bladder will occur as is the case with exstrophy of bladder. However pyocystitis may or may not develop on follow up. A $60 \mathrm{~cm}$ ileum was used and divided into three segments. $40 \mathrm{cms}$ for reservoir and $10 \mathrm{cms}$ each for afferent and efferent limbs and stoma was brought through umbilicus (Figure 3). On follow up after 06 months upper tracts were evualated and reservoir was reconstructed (Figure 4) using radiocontrast studies. Patient is continent both day and night

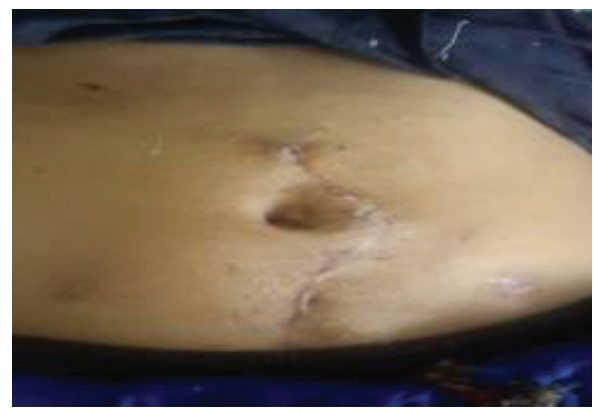

Figure 3: Concealed Stoma for Cathterization.

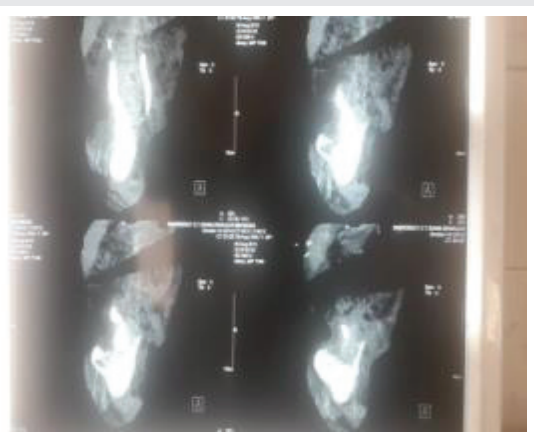

Figure 4: 3D reconstruction of Cutaneous continent lleal Neobladder. 
with catheterization interval of $4 \mathrm{hrs}$ and enjoying an excellent lifestyle, accepted body image and good personal satisfaction. As bowel is used for neobladder needs long term follow up for metabolic complications and even malignancy.

\section{Conclusion}

The case is presented here because of its rarity and to emphasize upon careful examination and proper reconstruction of an incontinent child, providing them proper treatment, to reduce psychosocial problems. Moreover a cutaneous continent catheterizable stoma is a viable option in patients with early failed reconstruction in female epispadias.

\section{References}

1. Elder JS (2007) Anomalies of the bladder. In: Kliegman, Jenson, Beharman, Stanton. Nelson textbook of Pediatrics. 18th ed. Philadelphia: Saunders 22432245.

2. Gearhart JP ( 2009) The bladder exstrophy-epispadias-cloaca exstrophy complex. Pediatric Urology 386-415. Link: https://bit.ly/2KtWRGp

3. Ebert AK, Reutter H, Ludwig M, Rosch WH (2009) The exstrophy-epispadias complex. Orphanet J Rare Dis 4: 23. Link: https://bit.ly/2VxIW9B

4. Mollard P, Basset T, Mure PY (1997) Female epispadias. J Urol 158: 1543 1546. Link: https://bit.ly/3eLVfFL
Discover a bigger Impact and Visibility of your article publication with

Peertechz Publications
Highlights

* Signatory publisher of ORCID

* Signatory Publisher of DORA (San Francisco Declaration on Research Assessment)

* Articles archived in worlds' renowned service providers such as Portico, CNKI, AGRIS, TDNet, Base (Bielefeld University Library), CrossRef, Scilit, J-Gate etc.

* Journals indexed in ICMJE, SHERPA/ROMEO, Google Scholar etc.

* OAI-PMH (Open Archives Initiative Protocol for Metadata Harvesting)

* Dedicated Editorial Board for every journal

* Accurate and rapid peer-review process

* Increased citations of published articles through promotions

* Reduced timeline for article publication

Submit your articles and experience a new surge in publication services (https://www.peertechz.com/submission).

Peertechz journals wishes everlasting success in your every endeavours.

Copyright: @ 2020 Khawaja AR, et al. This is an open-access article distributed under the terms of the Creative Commons Attribution License, which permits unrestricted use, distribution, and reproduction in any medium, provided the original author and source are credited. 